\title{
The prognostic value of IDO expression in solid tumors: a systematic review and meta-analysis
}

\author{
Sen Wang ${ }^{1,2+}$, Jia $\mathrm{Wu}^{1 \dagger}$, Han Shen ${ }^{2^{*}}$ and Junjun Wang ${ }^{1 *}$
}

\begin{abstract}
Background: Indoleamine 2,3-dioxygenase (IDO) is a rate-limiting enzyme in the metabolism of tryptophan into kynurenine. It is considered to be an immunosuppressive molecule that plays an important role in the development of tumors. However, the association between IDO and solid tumor prognosis remains unclear. Herein, we retrieved relevant published literature and analyzed the association between IDO expression and prognosis in solid tumors.
\end{abstract}

Methods: Studies related to IDO expression and tumor prognosis were retrieved using PMC, EMbase and web of science database. Overall survival (OS), time to tumor progression (TTP) and other data in each study were extracted. Hazard ratio (HR) was used for analysis and calculation, while heterogeneity and publication bias between studies were also analyzed.

Results: A total of 31 studies were included in this meta-analysis. Overall, high expression of IDO was significantly associated with poor OS (HR 1.92, 95\% Cl 1.52-2.43, $P<0.001)$ and TTP (HR $2.2595 \% \mathrm{Cl} 1.58-3.22, P<0.001)$. However, there was significant heterogeneity between studies on OS $\left(I^{2}=81.1 \%, P<0.001\right)$ and TTP $\left(I^{2}=54.8 \%, P=\right.$ 0.007). Subgroup analysis showed lower heterogeneity among prospective studies, studies of the same tumor type, and studies with follow-up periods longer than 45 months.

Conclusions: The high expression of IDO was significantly associated with the poor prognosis of solid tumors, suggesting that it can be used as a biomarker for tumor prognosis and as a potential target for tumor therapy.

Keywords: Meta-analysis, IDO, Solid tumor, Survival

\section{Background}

Indoleamine 2,3-dioxygenase (IDO) is an intracellular and immunosuppressive rate-limiting enzyme in metabolism of tryptophan to kynurenine [1]. Tryptophan is an essential amino acid in protein synthesis and many important metabolic processes and cannot be synthesized in vivo. The main metabolic pathway for tryptophan in

\footnotetext{
*Correspondence: wangjunjun9202@163.com; shenhan10366@sina.com † Sen Wang and Jia Wu contributed equally to this work.

'Department of Clinical Laboratory Medicine, Jinling Hospital, Medical School of Nanjing University, Nanjing 210002, China

2Department of Clinical Laboratory Medicine, Nanjing Drum Tower Hospital, Medical School of Nanjing University, Nanjing 210008, China
}

mammals is the kynurenine pathway, and this pathway requires participation of members from the IDO family. The IDO family of genes includes IDO1 and IDO2. IDO1 has higher catalytic efficiency than IDO2 and is more abundant in tissues [2]. In this systematic review and meta-analysis, the term 'IDO' will refer to IDO1.

IDO can exert immunosuppressive effects through a variety of mechanisms. The high expression and activity of IDO leads to a large consumption of tryptophan in the cell microenvironment, which makes the cells in a "tryptophan starvation" state. Depletion of tryptophan causes $\mathrm{T}$ cells arrest in the G1 phase of cell cycle,

(c) The Author(s). 2020 Open Access This article is licensed under a Creative Commons Attribution 4.0 International License, which permits use, sharing, adaptation, distribution and reproduction in any medium or format, as long as you give appropriate credit to the original author(s) and the source, provide a link to the Creative Commons licence, and indicate if changes were made. The images or other third party material in this article are included in the article's Creative Commons licence, unless indicated otherwise in a credit line to the material. If material is not included in the article's Creative Commons licence and your intended use is not permitted by statutory regulation or exceeds the permitted use, you will need to obtain permission directly from the copyright holder. To view a copy of this licence, visit http://creativecommons.org/licenses/by/4.0/. The Creative Commons Public Domain Dedication waiver (http://creativecommons.org/publicdomain/zero/1.0/) applies to the data made available in this article, unless otherwise stated in a credit line to the data. 
thereby inhibiting $\mathrm{T}$ cell proliferation. The main metabolite of tryptophan degradation, kynurenine, also has a direct toxic effect on $\mathrm{T}$ cells and induces $\mathrm{T}$ cell apoptosis. Kynurenine is also a natural ligand for aryl hydrocarbon receptors. By activating aryl hydrocarbon receptors, kynurenine can regulate the differentiation direction of Th17/Treg cells, thereby promoting the balanced differentiation of Th17/Treg to Treg cells [3-5].

IDO plays an important role in a variety of disease processes such as chronic inflammatory diseases, infection, and cancer [4, 6-8]. Increased expression of IDO is observed in many types of tumors, including colorectal, hepatocellular, ovarian and melanomas [5]. Tumors with high expression of IDO tend to increase metastatic invasion and have a poor clinical outcome in cancer patients. IDO is considered to be a new target for tumor therapy, and inhibition of IDO activity by using IDO inhibitors can increase patient survival [9-11].

Although IDO-targeted tumor therapy strategies are currently being developed, the association between expression level of IDO in tumor tissues and prognosis of patients remains unclear. Therefore, we constructed this meta-analysis to explore the correlation between IDO expression and tumor prognosis.

\section{Methods}

\section{Search strategy}

The present systematic review and meta-analysis was conducted and reported according to the standards of quality detailed in the Preferred Reporting Items for Systematic Reviews and Meta-Analyses (PRISMA) statement [12]. Comprehensive and systematic search of published literature using the following database, such as PMC, Embase, and Web of Science (up to May 31, 2019). We used keyword such as: ("IDO" or Indoleamine 2,3-dioxygenase) AND (cancer or carcinoma or tumor or neoplasms) AND prognosis to search in the database. The retrieved information of relevant literature was downloaded and imported into the literature management software for further browsing and screening.

\section{Inclusion criteria}

Studies included in this meta-analysis needed to meet the following inclusion criteria: 1) The included literature needed to provide appropriate prognostic indicators in evaluating the expression of IDO and prognosis of solid tumors, such as overall survival (OS), progression-free survival (PFS), disease-free survival (DFS) or relapse-free survival (RFS). 2) The included literature needed to provide hazard ratios (HRs) with 95\% confidence intervals (CIs). 3) The included literature needed to provide criteria for defining IDO expression as positive and negative, or strong and weak expression.

\section{Exclusion criteria}

This meta-analysis had the following exclusion criteria: 1) The type of literature was not a research article but the following types:reviews, case reports, letters, editorials, and meeting abstracts; 2) Animal experiments or in vitro experiments rather than patient-based clinical studies; 3) HRs and 95\% CI were not directly provided in the study; 4) Research was not published in English; 5) Sample size was too small, less than 50; 6) IDO expression was not detected in tumor tissues.

\section{Data extraction}

The data extraction included in the studies were independently completed by two researchers according to the same criteria, and if there was inconsistency, a group discussion was conducted. This meta-analysis used two outcome endpoints: OS (overall survival) and TTP (time to tumor progression). Since PFS, DFS and RFS are similar outcome endpoints, we in this meta-analysis used the same prognostic parameter TTP to represent them. We extracted the following information from each study: first author's name, publication year, country, cancer type, case number, study type, IDO detection method, cut off values for IDO expression, endpoints and HR. When the study provided HR for both univariate and multivariate analyses, we preferred results from multivariate analysis. The main features for these eligible studies are summarized in Fig. 1. Quality assessment for the included studies using the Newcastle-Ottawa Scale (NOS) [13]. According to the NOS system, the quality judgment for the studies were based on three parts: selection of study groups (4 points), comparability of study groups (2points), and outcome assessment (3 points). Studies with NOS scores above 5 were considered to have higher quality.

\section{Statistical analysis}

Combined HR and 95\% CI were used to assess the effect of IDO expression on tumor prognosis. HR > 1 and $95 \%$ $\mathrm{CI}$ did not overlap 1 indicating that overexpression of IDO had a negative impact on tumor prognosis. Heterogeneity analysis using the $\mathrm{Q}$ test, and $P<0.1$ was considered statistically significant. The heterogeneity was evaluated according to $\mathrm{I}^{2}$. When $\mathrm{I}^{2}$ was $0-50 \%$, it showed no or moderate heterogeneity, and when $\mathrm{I}^{2}>$ $50 \%$, it showed significant heterogeneity. According to the $\mathrm{I}^{2}$ and $P$ values, different effect models were used. When $\mathrm{I}^{2}>50 \%$, or $P<0.1$, a random effects model was used. Otherwise we used a fixed effect model when the heterogeneity was low or there was no heterogeneity. Begg's test and Egger's test were used to determine if there was a potential publication bias in the selected studies. Sensitivity analysis was used to assesse the stability of results by excluding one study at a time. All 


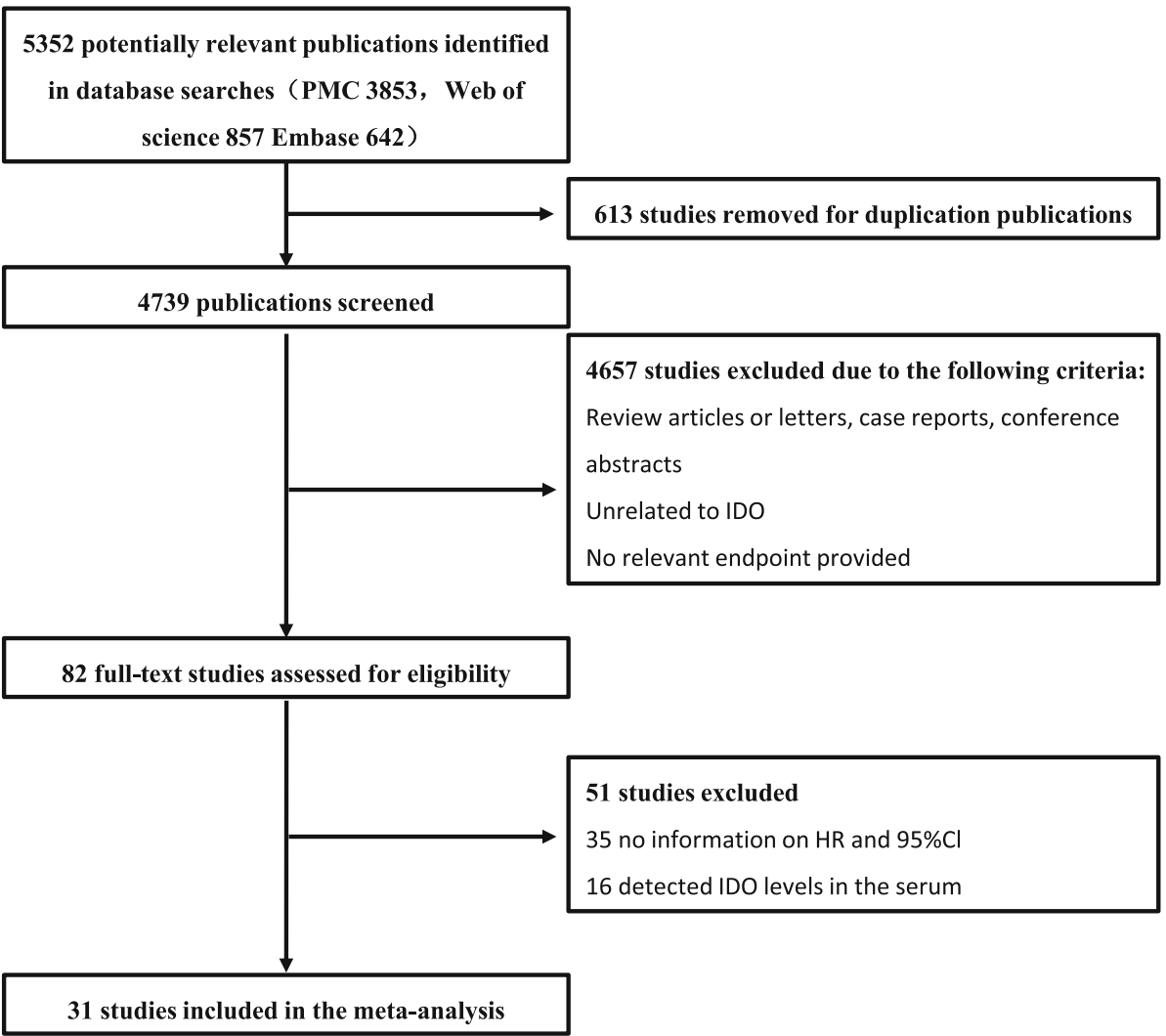

Fig. 1 The flow chart of the selection process in our meta-analysis

statistical analysis and data generation were done using STATA software (StataMP 14, USA).

\section{Results}

Description of selected studies

Figure 1 shows our literature search and screening strategy. After removing 613 duplicate studies, a total of 4739 studies were further explored for the title and abstract. A total of 4657 studies were excluded due to non-conformity or irrelevant topics. 82 studies conducted further full-text evaluations, 35 of which were excluded due to lack of HR information on HR and 95\% $\mathrm{Cl}, 16$ studies were excluded because of detected IDO levels in the serum. Therefore, the final 31 studies included a total of 3939 patients for meta-analysis to analyze the association between IDO expression and prognosis in solid tumor patients [14-44].

The 31 studies included in this meta-analysis were derived from 10 countries, 6 studies originating from Europe (respectively from Belgium, Netherlands, Poland, Croatia and Germany), 18 from Asia (10 from China; and 8 from Japan), 2 from Africa (Tunisia), 3 from USA, 2 from Australia. All of these studies were published between 2006 and 2019. As for the cancer types, among the studies, esophageal cancer was the most common type of cancer $(n=4)$, followed by endometrial cancer, colorectal cancer, melanoma, and vulvar squamous cell carcinoma $(n=2)$. Other tumor types were involved in one study each. Since PFS, DFS and RFS are similar outcome endpoints, we used TTP to represent them in this meta-analysis. In these studies, 3 studies used polymerase chain reaction (qRT-PCR) to detect IDO expression in tumor tissues, while the other 28 studies used immunohistochemistry (IHC) staining to detect IDO expression. 28 datasets had information on OS, and 14 had information on TTP (PFS /DFS). According to NOS tool, we systematically evaluated the quality of the included studies, and all of these studies had high quality and the NOS scores were between 6 and 9 points. (Table 1).

\section{Impact of IDO expression on cancer prognosis}

In the included studies, a total of 28 studies analyzed the association between IDO expression and OS. Of these 28 studies, 3 studies with $\mathrm{HR}<1[38,39,41]$, and 18 studies with HR > $2[14-16,18-22,24,27,29,30,33,34$, $37,42-44]$. We performed a meta-analysis of 28 studies. Since $\mathrm{I}^{2}$ values was $81.1 \%$, the random effects model was used to calculate the pooled HR and 95\% CI. The combined analysis of 28 datasets indicated that compared 


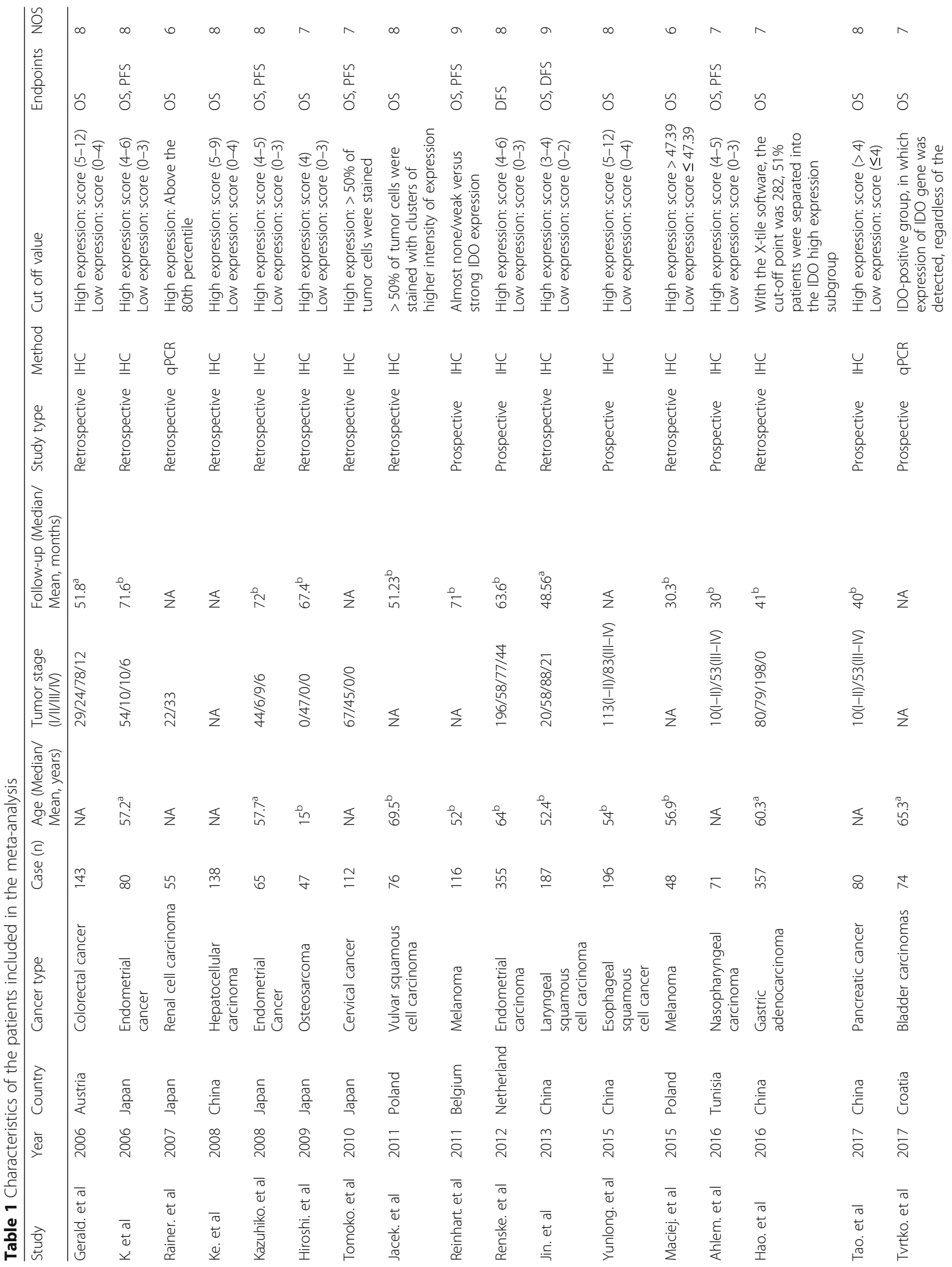




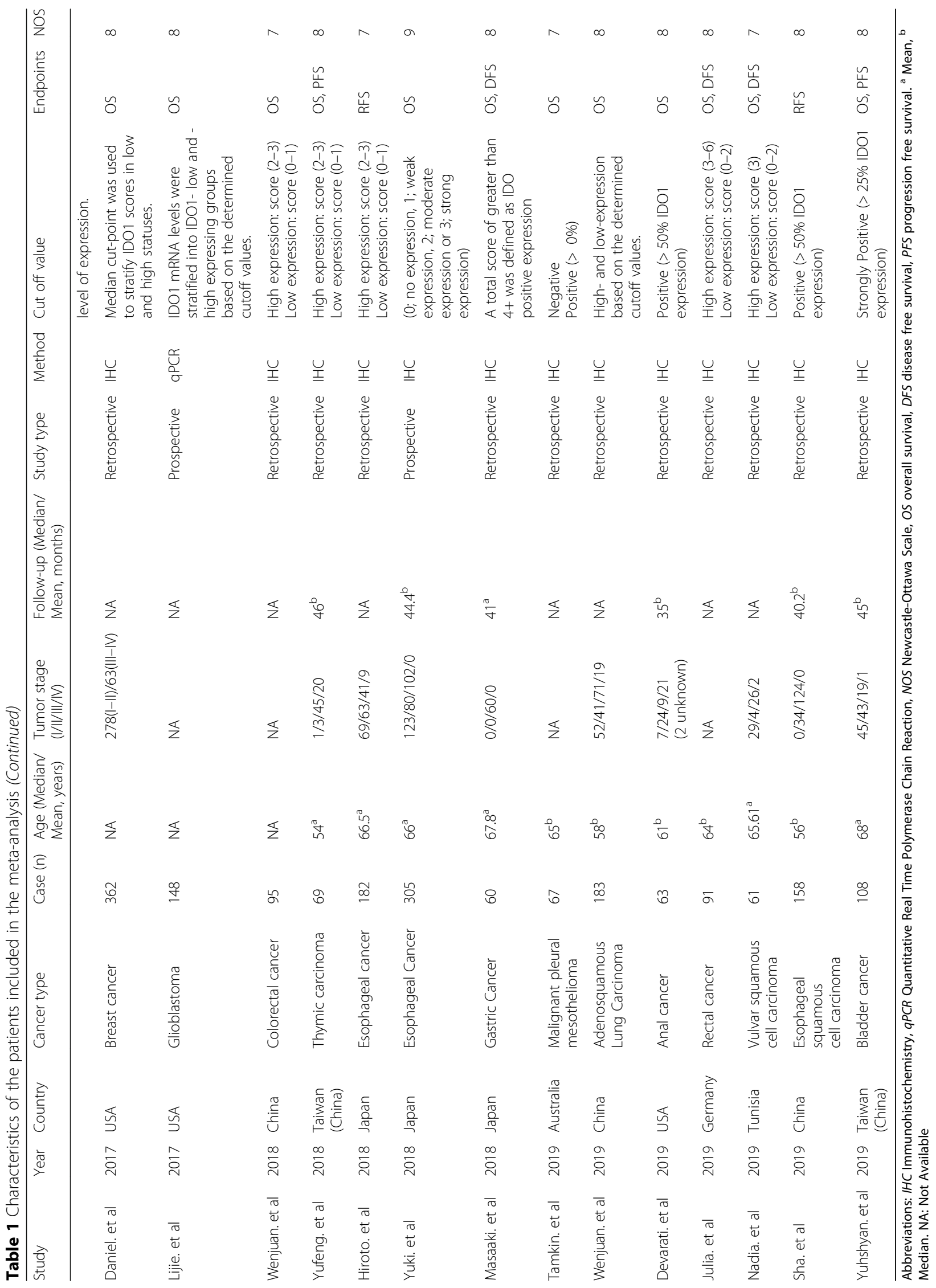


with IDO negative/low expression, IDO positivity/high expression was highly correlated with poor prognosis in cancer patients (pooled HR 1.92, 95\% CI 1.52-2.43, $P<$ 0.001 ) (Fig. 2). A total of 14 studies were used to assess the association between IDO expression and TTP. We calculated the pooled HR using a random effects model, because the heterogeneity test indicated an $\mathrm{I}^{2}$ value of $54.8 \%$ and a $P$ value of 0.007 . The results indicated that high expression of IDO was highly correlated with poor prognosis of TTP (pooled HR $=2.25,95 \%$ CI 1.58-3.22, $P<0.001)$ (Fig. 3).

\section{Subgroup analysis}

Since the results from the meta-analysis indicated significant heterogeneity, we performed heterogeneity analysis in order to identify potential factors that may cause heterogeneity. We classified the included studies and performed heterogeneity analysis based on study location, detection method, sample size, study type, cancer type, age, follow-up periods and study quality. Subgroup analysis showed that the high expression of IDO was highly correlated with poor OS and TTP, but the heterogeneity was not significantly reduced according to different study locations, detection method, sample size grouping, average age and study quality. However, in a prospective study group, we found that high expression of IDO was highly correlated with poor OS prognosis (HR1.98, 95\% CI 1.57-2.49, $P<0.001$ ) and there was no heterogeneity $\left(\mathrm{I}^{2}=0 \%, P=0.6\right)$ (Table 2$)$. Subgroup analysis showed that there was no heterogeneity among bladder cancer, colorectal cancer, endometrial cancer and esophageal cancer studies. Heterogeneity was also significantly reduced among studies of the same type of tumor, such as digestive system tumors and reproductive system tumors (Table 2). In addition, there was no significant heterogeneity (HR 3.41, 95\% CI 2.41-4.83, $P<$ $0.001 . \mathrm{I}^{2}=0 \%, P=0.97$ ) between studies with an average follow-up period of more than 45 months (Table 2).

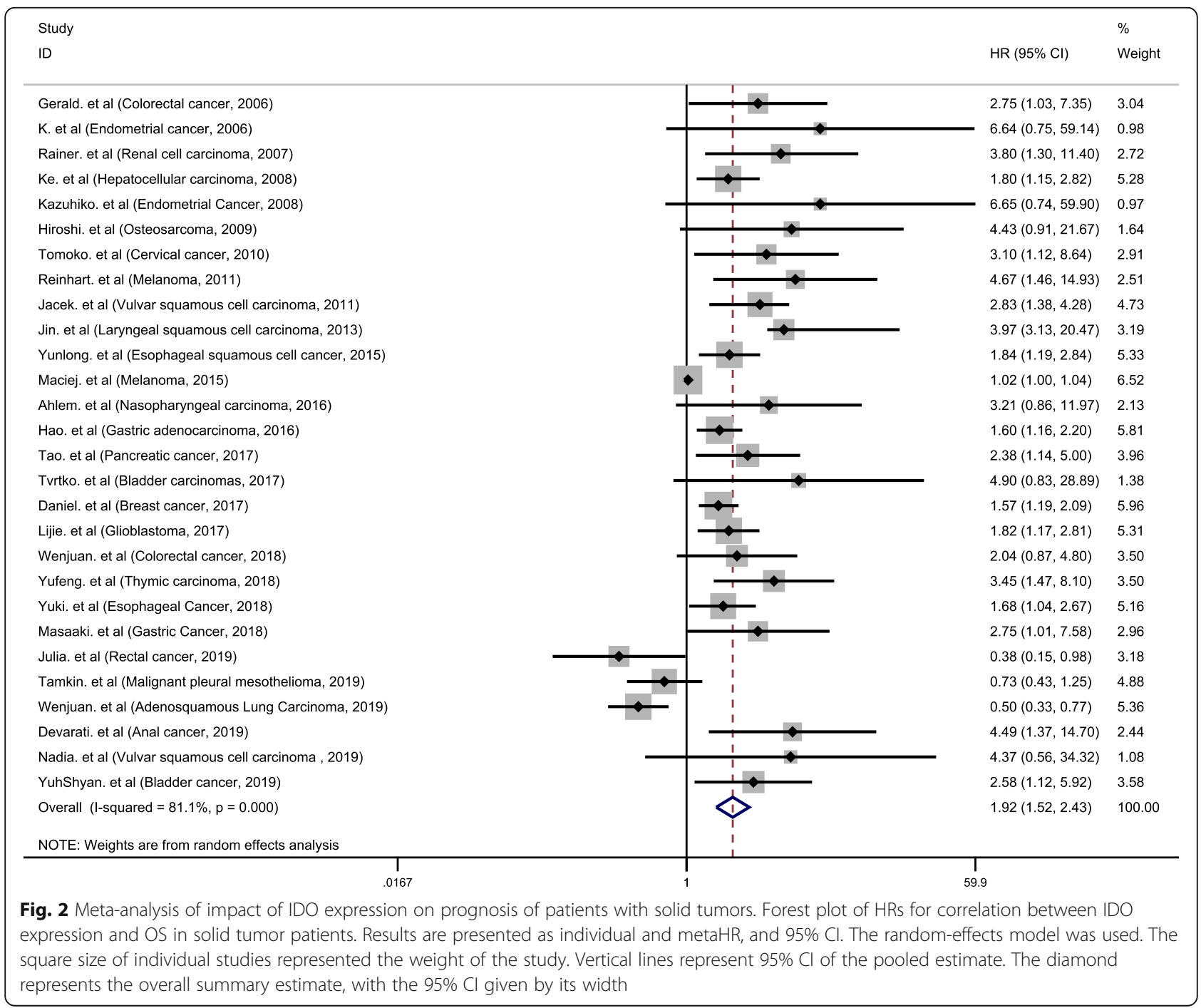




\begin{tabular}{|c|c|c|c|}
\hline \multicolumn{2}{|l|}{ Study } & & $\%$ \\
\hline \multicolumn{2}{|l|}{ ID } & HR $(95 \% \mathrm{Cl})$ & Weight \\
\hline \multirow{2}{*}{ K. et al (Endometrial cancer, 2006) } & 1 & \multirow[b]{2}{*}{$12.04(1.48,97.79)$} & \multirow[b]{2}{*}{2.42} \\
\hline & & & \\
\hline Kazuhiko. et al (Endometrial Cancer, 2008) & & $6.32(1.73,54.80)$ & 3.29 \\
\hline Tomoko. et al (Cervical cancer, 2010) & to & $2.65(1.09,6.47)$ & 7.51 \\
\hline Reinhart. et al (Melanoma, 2011) & & $2.82(1.23,6.45)$ & 8.02 \\
\hline Renske. et al (Endometrial carcinoma, 2012) & 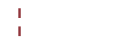 & $1.18(0.43,1.47)$ & 9.95 \\
\hline Jin. et al (Laryngeal squamous cell carcinoma, 2013) & & $3.26(1.97,19.36)$ & 5.78 \\
\hline Ahlem. et al (Nasopharyngeal carcinoma, 2016) & & $3.52(1.26,9.78)$ & 6.54 \\
\hline Yufeng. et al (Thymic carcinoma, 2018) & $\rightarrow$ & $2.57(1.12,5.87)$ & 8.03 \\
\hline Hiroto. et al (Esophageal cancer, 2018) & +1 & $1.41(0.80,2.58)$ & 10.23 \\
\hline Masaaki. et al (Gastric Cancer, 2018) & $\rightarrow$ & $2.17(0.88,5.35)$ & 7.43 \\
\hline Julia. et al (Rectal cancer, 2019) & 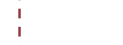 & $0.38(0.15,0.98)$ & 7.14 \\
\hline Nadia. et al (Vulvar squamous cell carcinoma, 2019) & $\rightarrow$ & $2.06(0.75,5.64)$ & 6.66 \\
\hline Sha. et al (Esophageal squamous cell carcinoma, 2019) & 1 & $3.55(1.93,6.54)$ & 9.99 \\
\hline YuhShyan. et al (Bladder cancer, 2019) & I & $3.80(1.46,9.86)$ & 7.03 \\
\hline Overall (I-squared $=54.8 \%, p=0.007$ ) & & $2.25(1.58,3.22)$ & 100.00 \\
\hline NOTE: Weights are from random effects analysis & 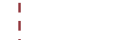 & & \\
\hline$\underset{.102}{T}$ & & & \\
\hline
\end{tabular}

\section{Publication bias and sensitivity analysis}

Evaluation of publication bias between studies was done using Begg's funnel plot and Egger's test. The shape of the OS and TTP funnel plots were not significantly asymmetrical, and the Egger's test indicated OS $(P=0.47)$ and TTP $(P=0.89)$. These results suggested that there was no significant publication bias in the meta-analysis of IDO expression in relation to OS and TTP prognosis (Fig. 4). Sensitivity analysis refers to the removal of a study each time to analyze the impact of individual studies on the stability of meta-analysis results. Sensitivity analysis showed that no single study had a significant impact on the conclusions of this meta-analysis (Fig. 5).

\section{Discussions}

In this study, we systematically assessed IDO expression level and prognostic indicators of 3939 solid tumor patients from 31 different studies. Our results showed that high expression of IDO predicted poor OS and TTP in cancer patients. However, the results from this metaanalysis indicated that there was significant heterogeneity among these studies. The Begg's funnel plot and Egger's test showed that there was no significant publication bias in this meta-analysis, and the sensitivity analysis showed that no single study can influence the conclusion of this meta-analysis.

High expression of IDO was highly correlated with poor prognosis of OS and TTP. However, the heterogeneity was also obvious. It was not difficult to understand that there will be heterogeneity in our study. In 31 studies, a total of 10 tumor types were included, and the role of IDO in different tumors may be inconsistent. For example, three studies have concluded to the contrary. In addition, the study type, IDO test method, number of patients included, follow-up period, and study quality were different in each study, all these factors can lead to heterogeneity. To this end, we performed a subgroup analysis to explore the source of heterogeneity. Subgroup analysis showed that the study location, sample size, and age were not sources of heterogeneity. For OS, no heterogeneity in prospective studies and follow-up period over 45 months studies. These results indicate that the type of study and follow-up period were the reasons for the heterogeneity in this meta-analysis. In addition, in the same type of tumor research (such as digestive system tumors and reproductive system tumors), there was no obvious heterogeneity. Subgroup analysis also showed no heterogeneity in bladder cancer, 
Table 2 Hazard ratio for the association between IDO overexpression and solid tumors prognosis

\begin{tabular}{|c|c|c|c|c|c|c|c|}
\hline \multirow[t]{2}{*}{ Stratified analysis } & \multirow{2}{*}{$\begin{array}{l}\text { Effect } \\
\text { size }\end{array}$} & \multirow{2}{*}{$\begin{array}{l}\text { NO. } \\
\text { of } \\
\text { study }\end{array}$} & \multirow[t]{2}{*}{ Cases } & \multicolumn{2}{|l|}{$H R$} & \multicolumn{2}{|c|}{ Heterogeneity } \\
\hline & & & & Pooled HR (95\% Cl) & $P$ value & $\bar{P}(\%)$ & $p$ value \\
\hline \multicolumn{8}{|l|}{ All studies } \\
\hline OS & OS & 28 & 3457 & $1.92(1.52-2.43)$ & $<0.001$ & 81.1 & $<0.001$ \\
\hline ТTP & TाP & 14 & 1815 & $2.25(1.58-3.22)$ & $<0.001$ & 54.8 & 0.007 \\
\hline \multicolumn{8}{|l|}{ Study location } \\
\hline \multirow[t]{2}{*}{ Asia } & OS & 16 & 2137 & $2.12(1.54-2.92)$ & $<0.001$ & 68.5 & $<0.001$ \\
\hline & TाP & 9 & 1121 & $2.48(1.74-3.55)$ & $<0.001$ & 11.4 & 0.342 \\
\hline \multirow[t]{2}{*}{ Other countries } & OS & 12 & 1320 & $1.66(1.17-2.37)$ & 0.005 & 82.2 & $<0.001$ \\
\hline & ТTP & 5 & 694 & $1.99(1.32-2.98)$ & 0.001 & 14.3 & 0.323 \\
\hline \multicolumn{8}{|l|}{ Detection method } \\
\hline \multirow[t]{2}{*}{$\mathrm{IHC}$} & OS & 25 & 3180 & $1.86(1.46-2.38)$ & $<0.001$ & 81.3 & $<0.001$ \\
\hline & TाP & 14 & 1815 & $2.25(1.58-3.22)$ & $<0.001$ & 54.8 & 0.007 \\
\hline $\mathrm{qPCR}$ & OS & 3 & 277 & $2.11(1.42-3.13)$ & $<0.001$ & 17.7 & 0.297 \\
\hline \multicolumn{8}{|l|}{ Sample size } \\
\hline \multirow[t]{2}{*}{$<70$} & OS & 9 & 535 & $2.25(1.31-3.88)$ & 0.003 & 75.5 & $<0.001$ \\
\hline & TाP & 4 & 255 & $2.49(1.51-4.10)$ & $<0.001$ & 0.0 & 0.72 \\
\hline \multirow[t]{2}{*}{$70-120$} & OS & 10 & 903 & $2.37(1.42-3.95)$ & 0.001 & 55.9 & 0.02 \\
\hline & TाP & 6 & 578 & $2.43(1.09-5.44)$ & 0.03 & 72.8 & 0.003 \\
\hline \multirow[t]{2}{*}{$>140$} & OS & 9 & 2019 & $1.60(1.18-2.18)$ & 0.003 & 75.8 & $<0.001$ \\
\hline & TTP & 4 & 882 & $1.98(1.12-3.51)$ & 0.019 & 63.2 & 0.043 \\
\hline \multicolumn{8}{|l|}{ Study type } \\
\hline \multirow[t]{2}{*}{ Retrospective } & OS & 21 & 2807 & $1.82(1.39-2.40)$ & $<0.001$ & 81.5 & $<0.001$ \\
\hline & TTP & 11 & 1273 & $2.32(1.50-3.60)$ & $<0.001$ & 57.9 & 0.008 \\
\hline \multirow[t]{2}{*}{ Prospective } & OS & 7 & 650 & $1.98(1.57-2.49)$ & $<0.001$ & 0 & 0.6 \\
\hline & TाP & 3 & 542 & $2.09(1.03-4.23)$ & 0.04 & 56.2 & 0.102 \\
\hline \multicolumn{8}{|l|}{ Cancer type } \\
\hline Digestive system tumor & OS & 10 & 1528 & $1.79(1.38-2.31)$ & $<0.001$ & 40.8 & 0.085 \\
\hline Reproductive system tumor & OS & 6 & 756 & $2.39(1.53-3.72)$ & $<0.001$ & 34.9 & 0.175 \\
\hline Bladder cancer & OS & 2 & 182 & $2.90(1.32-6.15)$ & 0.006 & 0.0 & 0.521 \\
\hline Colorectal cancer & OS & 2 & 238 & $2.32(1.22-4.42)$ & 0.01 & 0.0 & 0.655 \\
\hline Endometrial cancer & OS & 2 & 145 & $6.64(1.41-31.27)$ & 0.017 & 0.0 & 0.99 \\
\hline Esophageal cancer & OS & 2 & 501 & $1.76(1.28-2.43)$ & 0.001 & 0.0 & 0.79 \\
\hline Esophageal cancer & TTP & 2 & 340 & $2.23(0.91-5.49)$ & 0.081 & 77.9 & 0.033 \\
\hline Gastric Cancer & OS & 2 & 417 & $1.68(1.22-2.32)$ & 0.001 & 1.5 & 0.314 \\
\hline Melanoma & OS & 2 & 164 & $1.95(0.45-8.49)$ & 0.376 & 84.8 & 0.01 \\
\hline Vulvar squamous cell carcinoma & OS & 2 & 137 & $2.92(1.69-5.04)$ & $<0.001$ & 0.0 & 0.69 \\
\hline \multicolumn{8}{|l|}{ Age (Mean/Median) } \\
\hline$<60$ years & OS & 9 & 991 & $2.02(1.22-3.36)$ & 0.007 & 83.6 & $<0.001$ \\
\hline$>60$ years & OS & 10 & 1262 & $1.76(1.16-2.67)$ & 0.008 & 68.8 & 0.001 \\
\hline \multicolumn{8}{|l|}{ Follow-up (Median/Mean) } \\
\hline$\leq 45$ months & OS & 8 & 1092 & $1.90(1.29-2.78)$ & 0.001 & 79.4 & $<0.001$ \\
\hline$>45$ months & OS & 8 & 783 & $3.41(2.41-4.83)$ & $<0.001$ & 0.0 & 0.97 \\
\hline Study quality & & & & & & & \\
\hline NOS score $>7$ & OS & 18 & 2825 & $2.00(1.48-2.69)$ & $<0.001$ & 72.6 & $<0.001$ \\
\hline NOS score $\leq 7$ & OS & 10 & 632 & $1.75(1.20-1.57)$ & $<0.001$ & 72.4 & $<0.001$ \\
\hline
\end{tabular}

Abbreviations: $H R$ hazard ratio, $C l$ confidence interval, $O S$ overall survival, $T P$ time to tumor progression, $I H C$ Immunohistochemistry, $q P C R$ Quantitative Real Time Polymerase Chain Reaction 

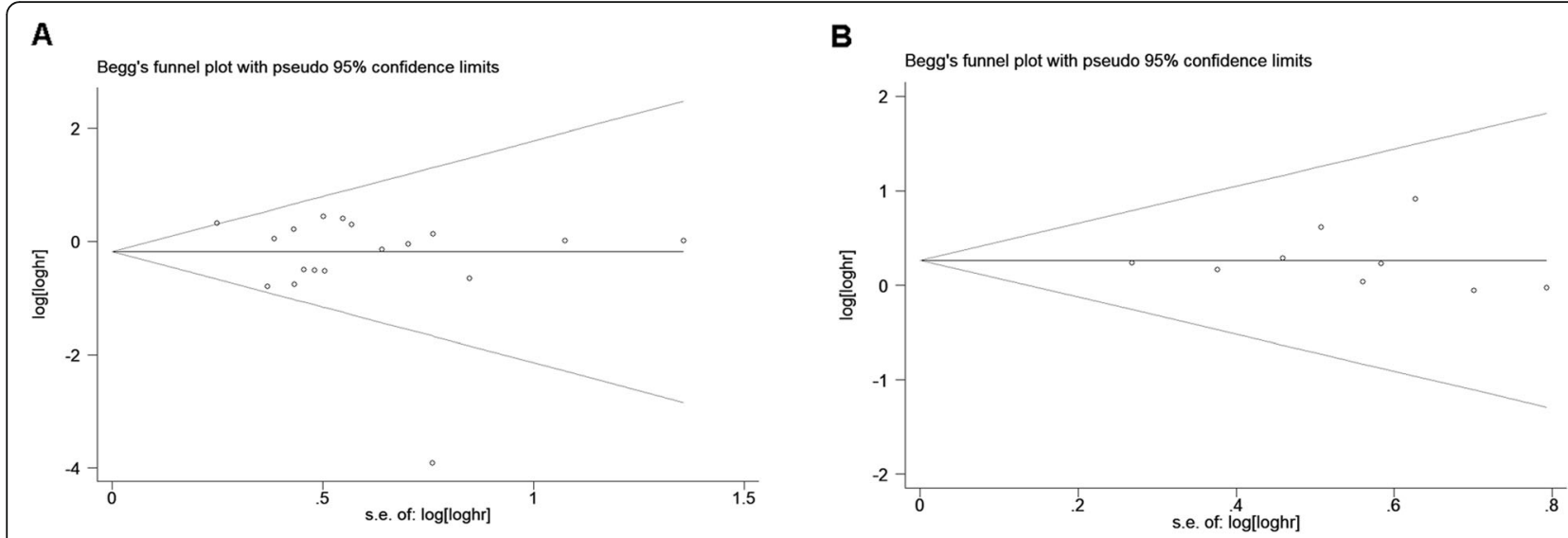

C

$\mathbf{D}$
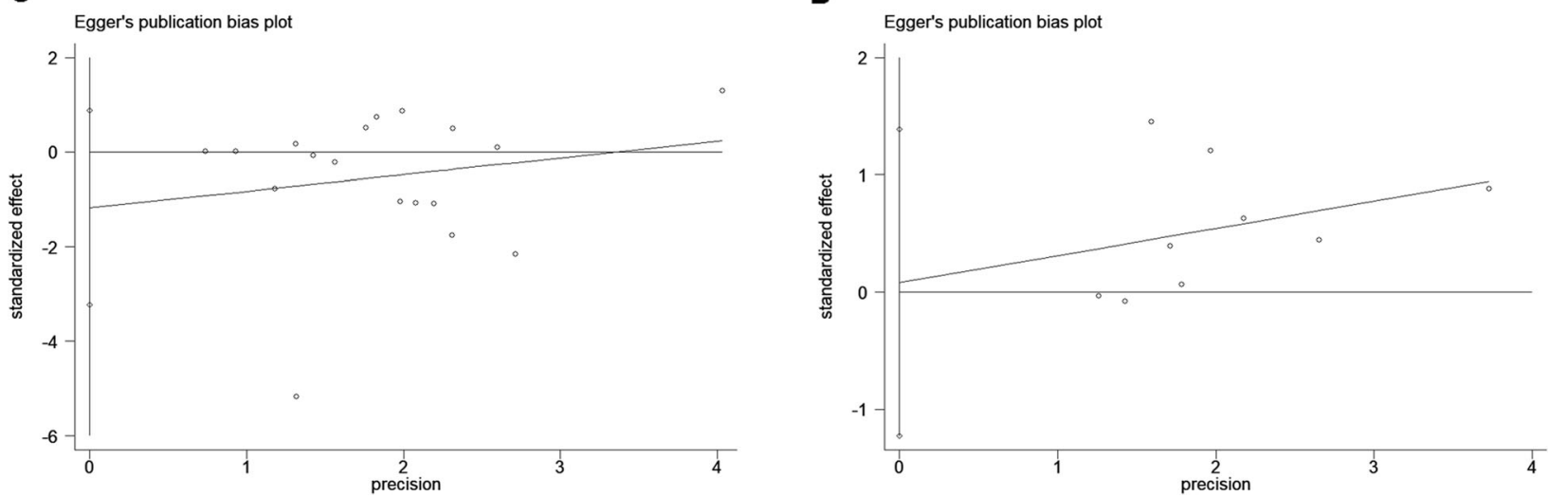

Fig. 4 Begg's funnel plots and Egger's publication bias plots for studies involved in the meta-analysis. Begg's funnel plots for the studies included in meta-analysis regarding. OS (a) and TTP (b). Each hazard ratio (HR) was plotted on an HR scale against its standard error (SE). The horizontal lines indicate the pooled estimate of the overall HR, with the sloping lines reflecting the expected $95 \%$ confidence interval for a given SE. Egger's publication bias plots for the studies included in meta-analysis regarding OS (c) and TTP (d). The 95\% confidence intervals of the regression line's y intercept include zero, $P$ values were 0.59 and 0.89 , respectively, indicating that there was no evidence of publication bias

colorectal cancer, endometrial cancer and esophageal cancer, gastric cancer and vulvar squamous cell carcinoma studies. The difference in study quality may also be the cause of heterogeneity. To this end, we used the NOS score to evaluate the quality of each study and performed a subgroup analysis based on the NOS score. We found that the high-scoring study group did not significantly reduce heterogeneity. Therefore, in this meta-analysis, the quality of study is not the main reason for heterogeneity.

Our study further enhanced the view that high expression of IDO has a poor prognosis for cancer patients by performing meta-analysis on a large number of research data. In addition, this meta-analysis also gives hints on several other aspects. First, the high expression of IDO may be a universal prognostic biomarker for solid tumors. We analyzed 10 different types of solid tumors, including colorectal cancer, endometrial cancer, renal cell carcinoma, hepatocellular carcinoma, etc. Secondly, we verified that both Asian patients and other country patients harboring high expression of IDO were highly correlated with poor prognosis in patients with solid tumors, which did not vary because of ethnic differences. Moreover, our results suggested that the IDO expression can be used as a more widely prognostic biomarker. Finally, this study suggested that IDO had the potential to develop into a prognostic biomarker and a therapeutic target for solid tumors.

It should be noted that, there were limitations in this meta-analysis. First, the definitions of IDO positive and high expression were not completely consistent between studies, which may cause heterogeneity between studies. Secondly, due to limitations from the other included studies and large number of tumor types, we were unable to perform a subgroup analysis for each type of tumor. Thirdly, we extracted the HRs data directly from the original literature, and these data were reliable than calculated HRs indirectly deducted from the literature. However, some studies did not provide complete data and were excluded from statistics, hence some missing 

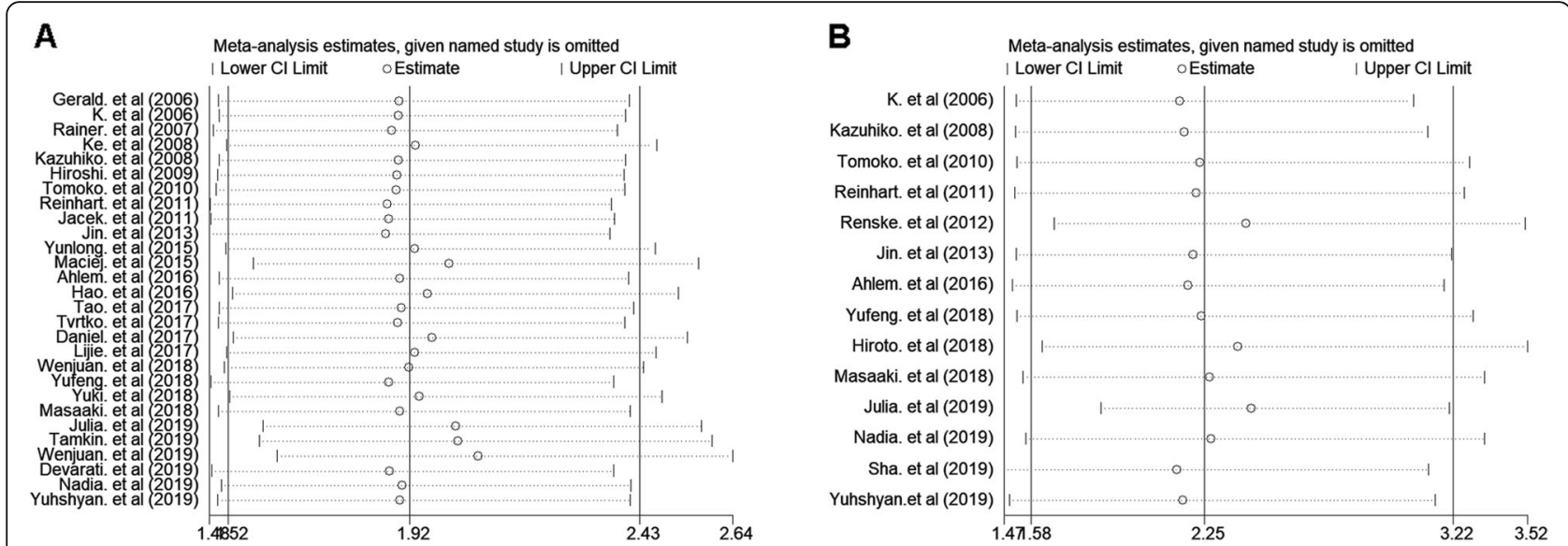

Fig. 5 Sensitivity analysis of the meta-analysis. a Overall survival. b Time to tumor progression. The vertical axis at 1.98 and 2.25 indicates the overall HR, and the vertical lines on either side of 1.98 and 2.25 indicate the $95 \% \mathrm{Cl}$. Every hollow round indicates the pooled HR when the left study was omitted in a meta-analysis with a random model. The two ends of every broken line represent the respective $95 \% \mathrm{Cl}$

information might have reduced the power of IDO as a prognostic biomarker in solid tumor patients.

\section{Conclusions}

In summary, this meta-analysis clearly demonstrated that the high expression of IDO in tumor tissues was closely related to poor survival of tumor patients. Our study suggested that IDO may be used as a potential tumor prognostic biomarker and tumor treatment target.

\section{Abbreviations}

IDO: Indoleamine 2,3-dioxygenase; OS: Overall survival; TTP: Time to progression; HR: Hazard ratio; Cl: Confidence interval; Tregs: Regulatory Tcells; 1-MT: 1-methyltryptophan; DSS: Disease-specific survival; RFS: Relapsefree survival; DFS: Disease-free survival; TTR: Time to recurrence; NOS: Newcastle-Ottawa Scale

\section{Acknowledgements}

Not applicable.

\section{Authors' contributions}

SW, HS and JJW conceived of the idea, designed the study, defined the search strategy and selection criteria, and were the major contributors in writing the manuscript. SW and JW performed the literature search and the analyses. All the authors contributed to the writing and editing of the manuscript. All authors read and approved the final manuscript, and ensured that this is the case.

\section{Funding}

This work is supported by the National Natural Science Foundation $(81601765,81572074)$ and Jiangsu Province Postdoctoral Science Foundation (1601155B), including the design of the study and collection, analysis, and interpretation of data and in writing the manuscript.

\section{Availability of data and materials}

All data generated or analyzed during this study are included in this published article. The datasets used and/or analysed during the current study available from the corresponding author on reasonable request.

\section{Ethics approval and consent to participate}

This research work constitutes a meta-analysis of published data and does not include any studies with human participants or animals performed by any of the authors. Hence, no informed consent was required to perform this study.

\section{Consent for publication}

Not applicable.

\section{Competing interests}

The authors declare that they have no competing interests.

Received: 29 October 2019 Accepted: 12 May 2020

Published online: 26 May 2020

\section{References}

1. Munn DH, Mellor AL. Indoleamine 2,3 dioxygenase and metabolic control of immune responses. Trends Immunol. 2013:34(3):137-43.

2. Ball HJ, Yuasa HJ, Austin CJ, Weiser S, Hunt NH. Indoleamine 2,3dioxygenase-2; a new enzyme in the kynurenine pathway. Int J Biochem Cell Biol. 2009;41(3):467-71.

3. Mbongue J, Nicholas D, Torrez T, Kim N, Firek A, Langridge W. The role of Indoleamine 2, 3-Dioxygenase in immune suppression and autoimmunity. Vaccines. 2015:3(3):703-29.

4. Nguyen NT, Nakahama T, Le DH, Van Son L, Chu HH, Kishimoto T. Aryl hydrocarbon receptor and Kynurenine: recent advances in autoimmune disease research. Front Immunol. 2014;5:551.

5. Munn DH, Mellor AL. IDO in the tumor microenvironment: inflammation, counter-regulation, and tolerance. Trends Immunol. 2016;37(3):193-207.

6. Boasso A, Herbeuval JP, Hardy AW, Anderson SA, Dolan MJ, Fuchs D, Shearer GM. HIV inhibits CD4+ T-cell proliferation by inducing indoleamine 2,3-dioxygenase in plasmacytoid dendritic cells. BLOOD. 2007;109(8):3351-9.

7. Mehraj V, Routy JP. Tryptophan catabolism in chronic viral infections: handling uninvited guests. Int J Tryptophan Res. 2015;8:41-8.

8. von Bubnoff $D$, Bieber $T$. The indoleamine 2,3-dioxygenase (IDO) pathway controls allergy. ALLERGY. 2012;67(6):718-25.

9. Platten M, von Knebel DN, Oezen I, Wick W, Ochs K. Cancer immunotherapy by targeting IDO1/TDO and their downstream effectors. Front Immunol. 2015:5:673.

10. Jiang $T$, Sun $Y$, Yin $Z$, Feng $S$, Sun L, Li Z. Research progress of indoleamine 2,3-dioxygenase inhibitors. Future Med Chem. 2015;7(2):185-201.

11. Liu X, Newton RC, Friedman SM, Scherle PA. Indoleamine 2,3-dioxygenase, an emerging target for anti-cancer therapy. Curr Cancer Drug Targets. 2009; 9(8):938-52.

12. Moher D, Liberati A, Tetzlaff J, Altman DG. Preferred reporting items for systematic reviews and meta-analyses: the PRISMA statement. Int J Surg 2010;8(5):336-41. 
13. Stang A. Critical evaluation of the Newcastle-Ottawa scale for the assessment of the quality of nonrandomized studies in meta-analyses. Eur J Epidemiol. 2010;25(9):603-5.

14. Brandacher G. Prognostic value of Indoleamine 2,3-Dioxygenase expression in colorectal Cancer: effect on tumor-infiltrating T cells. Clin Cancer Res. 2006;12(4):1144-51.

15. Ino K, Yoshida N, Kajiyama H, Shibata K, Yamamoto E, Kidokoro K, Takahashi N, Terauchi M, Nawa A, Nomura S, et al. Indoleamine 2,3-dioxygenase is a novel prognostic indicator for endometrial cancer. Br J Cancer. 2006;95(11):1555-61.

16. Riesenberg R, Weiler C, Spring O, Eder M, Buchner A, Popp T, Castro M, Kammerer R, Takikawa O, Hatz RA, et al. Expression of indoleamine 2,3dioxygenase in tumor endothelial cells correlates with long-term survival of patients with renal cell carcinoma. Clin Cancer Res. 2007;13(23):6993-7002.

17. Pan K, Wang H, Chen MS, Zhang HK, Weng DS, Zhou J, Huang W, Li JJ, Song HF, Xia JC. Expression and prognosis role of indoleamine 2,3dioxygenase in hepatocellular carcinoma. J Cancer Res Clin Oncol. 2008; 134(11):1247-53.

18. Ino K, Yamamoto E, Shibata K, Kajiyama H, Yoshida N, Terauchi M, Nawa A, Nagasaka T, Takikawa O, Kikkawa F. Inverse correlation between tumoral indoleamine 2,3-dioxygenase expression and tumor-infiltrating lymphocytes in endometrial cancer: its association with disease progression and survival. Clin Cancer Res. 2008;14(8):2310-7.

19. Urakawa H, Nishida $Y$, Nakashima H, Shimoyama $Y$, Nakamura S, Ishiguro N. Prognostic value of indoleamine 2,3-dioxygenase expression in high grade osteosarcoma. CLIN EXP METASTAS. 2009;26(8):1005-12.

20. Inaba T, Ino K, Kajiyama H, Shibata K, Yamamoto E, Kondo S, Umezu T, Nawa A, Takikawa O, Kikkawa F. Indoleamine 2,3-dioxygenase expression predicts impaired survival of invasive cervical cancer patients treated with radical hysterectomy. Gynecol Oncol. 2010;117(3):423-8.

21. Sznurkowski JJ, Awrocki A, Emerich J, Sznurkowska K, Biernat W. Expression of indoleamine 2,3-dioxygenase predicts shorter survival in patients with vulvar squamous cell carcinoma (vSCC) not influencing on the recruitment of FOXP3-expressing regulatory T cells in cancer nests. Gynecol Oncol. 2011; 122(2):307-12

22. Speeckaert $R$, Vermaelen $K$, van Geel N, Autier P, Lambert J, Haspeslagh M, van Gele M, Thielemans K, Neyns B, Roche N, et al. Indoleamine 2,3dioxygenase, a new prognostic marker in sentinel lymph nodes of melanoma patients. Eur J Cancer. 2012;48(13):2004-11.

23. de Jong RA, Kema IP, Boerma A, Boezen HM, van der Want JJ, Gooden MJ, Hollema H, Nijman HW. Prognostic role of indoleamine 2,3-dioxygenase in endometrial carcinoma. Gynecol Oncol. 2012;126(3):474-80.

24. Ye J, Liu H, Hu Y, Li P, Zhang G, Li Y. Tumoral indoleamine 2,3-dioxygenase expression predicts poor outcome in laryngeal squamous cell carcinoma. Virchows Arch. 2013;462(1):73-81

25. Jia $Y$, Wang $H$, Wang $Y$, Wang $T$, Wang $M$, Ma M, Duan $Y$, Meng $X$, Liu L. Low expression of Bin1, along with high expression of IDO in tumor tissue and draining lymph nodes, are predictors of poor prognosis for esophageal squamous cell cancer patients. Int J Cancer. 2015;137(5):1095-106.

26. Pelak MJ, Śnietura M, Lange D, Nikiel B, Pecka KM. The prognostic significance of indoleamine-2,3-dioxygenase and the receptors for transforming growth factor $\beta$ and interferon $\gamma$ in metastatic lymph nodes in malignant melanoma. Pol J Pathol. 2015;4:376-82.

27. Ben-Haj-Ayed A, Moussa A, Ghedira R, Gabbouj S, Miled S, Bouzid N, TebraMrad S, Bouaouina N, Chouchane L, Zakhama A, et al. Prognostic value of indoleamine 2,3-dioxygenase activity and expression in nasopharyngeal carcinoma. Immunol Lett. 2016;169:23-32.

28. Liu H, Shen Z, Wang Z, Wang X, Zhang H, Qin J, Qin X, Xu J, Sun Y. Increased expression of IDO associates with poor postoperative clinical outcome of patients with gastric adenocarcinoma. Sci Rep. 2016;6:21319.

29. Zhang T, Tan XL, Xu Y, Wang ZZ, Xiao CH, Liu R. Expression and prognostic value of Indoleamine 2,3-dioxygenase in pancreatic Cancer. Chin Med J. 2017;130(6):710-6

30. Hudolin T, Mengus C, Coulot J, Kastelan Z, El-Saleh A, Spagnoli GC. Expression of Indoleamine 2,3-Dioxygenase gene is a feature of poorly differentiated non-muscle-invasive Urothelial cell bladder carcinomas. Anticancer Res. 2017;37(3):1375-80.

31. Carvajal-Hausdorf DE, Mani N, Velcheti V, Schalper KA, Rimm DL. Objective measurement and clinical significance of IDO1 protein in hormone receptor-positive breast cancer. J IMMUNOTHER CANCER. 2017:5(1):81.

32. Zhai L, Ladomersky E, Lauing KL, Wu M, Genet M, Gritsina G, Gyorffy B, Brastianos PK, Binder DC, Sosman JA, et al. Infiltrating T cells increase IDO1 expression in Glioblastoma and contribute to decreased patient survival. Clin Cancer Res. 2017;23(21):6650-60.

33. Ma W, Wang X, Yan W, Zhou Z, Pan Z, Chen G, Zhang R. Indoleamine-2,3-dioxygenase 1/cyclooxygenase 2 expression prediction for adverse prognosis in colorectal cancer. WORLD J GAST ROENTERO. 2018;24(20):2181-90.

34. Wei Y, Chu C, Chang C, Lin S, Su W, Tseng Y, Lin C, Yen Y. Different pattern of PD-L1, IDO, and FOXP3 Tregs expression with survival in thymoma and thymic carcinoma. Lung Cancer. 2018;125:35-42.

35. Takeya H, Shiota T, Yagi T, Ohnishi K, Baba Y, Miyasato Y, Kiyozumi Y, Yoshida N, Takeya M, Baba H, et al. High CD169 expression in lymph node macrophages predicts a favorable clinical course in patients with esophageal cancer. Pathol Int. 2018;68(12):685-93.

36. Kiyozumi $Y$, Baba $Y$, Okadome $K$, Yagi T, Ishimoto T, Iwatsuki M, Miyamoto $Y$, Yoshida N, Watanabe M, Komohara Y, et al. IDO1 expression is associated with immune tolerance and poor prognosis in patients with surgically resected esophageal cancer. Ann Surg. 2019;269(6):1101-8.

37. Nishi M, Yoshikawa K, Higashijima J, Tokunaga T, Kashihara H, Takasu C, Ishikawa D, Wada Y, Shimada M. The impact of Indoleamine 2,3dioxygenase (IDO) expression on stage III gastric Cancer. Anticancer Res. 2018;38(6):3387-92.

38. Ahmadzada T, Lee K, Clarke C, Cooper WA, Linton A, McCaughan B, Asher R Clarke S, Reid G, Kao S. High BIN1 expression has a favorable prognosis in malignant pleural mesothelioma and is associated with tumor infiltrating lymphocytes. Lung Cancer. 2019;130:35-41.

39. Ma W, Duan H, Zhang R, Wang X, Xu H, Zhou Q, Zhang L. High expression of Indoleamine 2, 3-Dioxygenase in Adenosquamous lung carcinoma correlates with favorable patient outcome. J Cancer. 2019;10(1):267-76.

40. Mitra D, Horick NK, Brackett DG, Mouw KW, Hornick JL, Ferrone S, Hong TS, Mamon H, Clark JW, Parikh AR, et al. High IDO1 expression is associated with poor outcome in patients with anal cancer treated with definitive chemoradiotherapy. Oncologist. 2019;24(6):e275-e283.

41. Schollbach J, Kircher S, Wiegering A, Seyfried F, Klein I, Rosenwald A, Germer C, Löb S. Prognostic value of tumour-infiltrating CD8+ lymphocytes in rectal cancer after neoadjuvant chemoradiation: is indoleamine-2,3dioxygenase (IDO1) a friend or foe? Cancer Immunol Immunother. 2019; 68(4):563-75

42. Boujelbene N, Ben Yahia H, Babay W, Gadria S, Zemni I, Azaiez H, Dhouioui S, Zidi N, Mchiri R, Mrad K, et al. HLA-G, HLA-E, and IDO overexpression predicts a worse survival of Tunisian patients with vulvar squamous cell carcinoma. HLA. 2019;94(1):11-24.

43. Zhou S, Zhao L, Liang Z, Liu S, Li Y, Liu S, Yang H, Liu M, Xi M. Indoleamine 2,3-dioxygenase 1 and programmed cell death-ligand 1 co-expression predicts poor pathologic response and recurrence in esophageal squamous cell carcinoma after neoadjuvant chemoradiotherapy. Cancers (Basel). 2019; 11(2):169.

44. Tsai Y, Jou Y, Tsai H, Cheong I, Tzai T. Indoleamine-2,3-dioxygenase-1 expression predicts poorer survival and up-regulates ZEB2 expression in human early stage bladder cancer. Urol Oncol. 2019;37(11):810.e17-27.

\section{Publisher's Note}

Springer Nature remains neutral with regard to jurisdictional claims in published maps and institutional affiliations.

Ready to submit your research? Choose BMC and benefit from:

- fast, convenient online submission

- thorough peer review by experienced researchers in your field

- rapid publication on acceptance

- support for research data, including large and complex data types

- gold Open Access which fosters wider collaboration and increased citations

- maximum visibility for your research: over $100 \mathrm{M}$ website views per year

At BMC, research is always in progress.

Learn more biomedcentral.com/submissions 